\title{
Endemic goitre and excessive iodine in urine and drinking water among Saharawi refugee children
}

\author{
Sigrun Henjum ${ }^{1, *}$, Ingrid Barikmo ${ }^{1}$, Anne Karine Gjerlaug ${ }^{1}$, Abderraháman Mohamed- \\ Lehabib $^{2}$, Arne Oshaug ${ }^{1}$, Tor Arne Strand ${ }^{3,4}$ and Liv Elin Torheim ${ }^{5}$ \\ ${ }^{1}$ Akershus University College, Box 423, N-2001 Lillestrøm, Norway: ${ }^{2}$ Saharawi Ministry of Health Tindouf, \\ Algeria: ${ }^{3}$ Centre for International Health, University of Bergen, Bergen, Norway: ${ }^{4}$ Medical Microbiology, \\ Department of Laboratory Medicine, Sykehuset Innlandet, Lillehammer, Norway: ${ }^{5}$ Fafo Institute for Applied \\ International Studies, Oslo, Norway
}

Submitted 12 May 2009: Accepted 17 February 2010: First published online 1 April 2010

\begin{abstract}
Objective: To assess the prevalence of enlarged thyroid volume (Tvol) in Saharawi refugee children, and their urinary iodine concentration (UIC), and to identify possible sources of excess iodine intake.

Design: A cross-sectional survey was performed during January-February 2007. Tvol was measured by ultrasound and iodine concentration was analysed in casual urine samples, in household drinking water and in milk samples from household livestock.

Setting: The study was undertaken in four refugee camps in the Algerian desert. Subjects: The subjects were 421 Saharawi children, 6-14 years old.

Results: Enlarged Tvol was found in 56\% (Tvol-for-age) and 86\% (Tvol-for-bodysurface-area) of the children. The median (25th percentile-75th percentile, $\left.\mathrm{P}_{25}-\mathrm{P}_{75}\right)$ UIC was $565(357-887) \mu \mathrm{g} / \mathrm{l}$. The median $\left(\mathrm{P}_{25}-\mathrm{P}_{75}\right)$ iodine concentration in household drinking water was 108 (77-297) $\mu \mathrm{g} / \mathrm{l}$. None of the children had UIC below $100 \mu \mathrm{g} / \mathrm{l}, 16 \%$ had UIC between 100 and $299 \mu \mathrm{g} / \mathrm{l}$, and $84 \%$ had UIC above $300 \mu \mathrm{g} / \mathrm{l}$. There was a positive association between Tvol and whether the household possessed livestock.

Conclusions: The children are suffering from endemic goitre and high UIC caused probably by an excessive intake of iodine. The excessive iodine intakes probably originate from drinking water and milk.
\end{abstract}

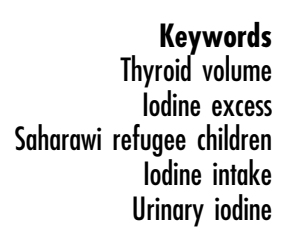

The relationship between iodine intake in a population and the occurrence of thyroid disease is U-shaped, with an increased risk with both low and high iodine intakes $^{(1)}$. Excessive dietary iodine may increase the risk of thyroiditis, hyperthyroidism, hypothyroidism and goitre $^{(2)}$. Refugees from Western Sahara have been living in the Algerian desert since $1975^{(3)}$. Studies among the refugees have revealed high prevalence of goitre by palpation, high urinary iodine concentration (UIC) and high levels of iodine in the main water sources ${ }^{(3-6)}$. Such high levels of iodine have been reported in only a few places in the world ${ }^{(7,8)}$. According to the WHO, a region is considered endemic if more than $5 \%$ of the population has goitre ${ }^{(9)}$. The goitre prevalence among the Saharawi seems largely to exceed this limit. Goitre is usually a problem of iodine deficiency. In the Saharawi population the contrary is probably the case. The objective of the present study was to assess the prevalence of enlarged thyroid volume (Tvol) in Saharawi refugee children, as well as their UIC, and to identify the sources of excess iodine intake in this population.

\section{Subjects and methods}

\section{Subjects}

A cross-sectional survey was performed in January and February 2007 in four Saharawi refugee camps near Tindouf in the Algerian desert. The estimated total population was approximately 165000 persons. Children aged from 6 to 14 years were the target group. Required sample size was derived from an assumed goitre prevalence of $50 \%$, an absolute precision of $\pm 5 \%$ and a $95 \%$ confidence interval. This corresponded to approximately 400 children (as determined with EpiInfo Statcalc version 6.04b; Centers for Disease Control and Prevention, Atlanta, GA, USA).

Each of the four camps was organised in six administrative zones called 'dairas', thus there were twenty-four dairas altogether. It was assumed that each daira had approximately the same number of inhabitants and hence seventeen children should be included from each daira $(400 / 24 \approx 17)$. Households in each daira were randomly selected until the required number of children from the 
daira was obtained. All eligible children in each selected household were included. This was taken into consideration in the data analysis. The average household had four children in the correct age groups, and about four households per daira were needed to reach the required number $(17 / 4 \approx 4)$. The response rate was $96 \%$, and the main reason for not participating was absence at the day of visit. The final sample consisted of 421 children (aged 6-14 years) from ninety-two households.

Ethical approval for the study was given by the Norwegian Regional Committees for Medical Research Ethics as well as by the Saharawi health authorities. It was emphasised that refusal to participate in the survey would have no negative impact on the refugees' entitlements to food aid or other services. Informed written consent was obtained from the chief medical officers of the camps and informed oral consent from the parents of the children in the study.

\section{Metbods}

Tvol was assessed using a portable ultrasound scanner (Sonosite Titan; Vingmed AS, Hovik, Norway) equipped with a $5-10 \mathrm{MHz}$ linear transducer, with a diameter of $38 \mathrm{~mm}$. Subjects were examined in a supine position with extended cervical spine. Maximum perpendicular depth (anteroposterior, AP diameter) and width (mediolateral, ML diameter) were measured with electronic callipers on a transverse image of the largest diameter. The maximum lobe length (craniocaudal, CC diameter) was measured on a longitudinal image; two images were used if the lobe extended beyond the $38 \mathrm{~mm}$ transducer measurement width. The transducer was kept perpendicular to the skin. Nodules and/or cystic areas were included in the Tvol determination. Thyroid volumetry was performed according to the method of Brunn et al. ${ }^{(10)}$. By regarding lobes as corrected rotation ellipsoids, the Tvol of each lobe was calculated as follows: $\mathrm{Tvol}=\mathrm{AP}$ diameter $\times \mathrm{ML}$ diameter $\times$ CC diameter $\times 0 \cdot 479$. The volumes of the two lobes, but not the isthmus, were included in the calculation of the total volume. A thyroid enlargement in a child was regarded as goitre if Tvol was above the 97th percentile $\left(\mathrm{P}_{97}\right)$ of the reference volumes in iodine-replete populations, corrected for sex, age (Tvol-for-age) or body surface area (BSA; Tvol-for-BSA) ${ }^{(11)}$.

Height and weight were measured by standard anthropometric techniques ${ }^{(12)}$. Body weight was measured to the nearest $0 \cdot 1 \mathrm{~kg}$ using a UNICEF electronic weighing scale (model 890; Seca, Hamburg, Germany) and height was measured to the nearest $0.1 \mathrm{~cm}$ using a portable stadiometer (UNICEF). For the measurements, the children removed their shoes, emptied their pockets and wore light indoor clothing. BSA was calculated as ${ }^{(13)}$ : BSA $\left(\mathrm{m}^{2}\right)=$ weight $(\mathrm{kg})^{0.425} \times$ height $(\mathrm{cm})^{0.725} \times 71.84 \times$ $10^{-4}$. A methodological sub-study was performed to assess inter- and intra-observer variability of the Tvol. Duplicate and repeated measurements were made by the two examiners in sixteen persons with the examiners being unaware of the results of the previous measurements. Based on the high inter-observer variability in the sub-study and a significantly different prevalence of children with enlarged Tvol between the examiners in the main study, the ultrasound images were printed out and re-measured. A systematic error was detected in the AP diameter of one of the examiners; it was measured too short and not perpendicular on the ML diameter. New AP and ML diameters were estimated and are presented in the current paper. A more detailed explanation of the correction of the measurement error is available (Henjum, manuscript in preparation).

Spot urine samples were collected from every child and aliquots were stored at $5^{\circ} \mathrm{C}$ until analysed. Water samples were collected in every household. Measurement of the iodine concentration in the urine and water samples was performed at the Nutritional Intervention Research Unit (NIRU) in Cape Town, South Africa, by means of manual acid digestion followed by the Sandell-Kolthoff reaction recorded spectrophotometrically ${ }^{(14)}$. A median UIC $>300 \mu \mathrm{g} / \mathrm{l}$ in 6- to 12-year-old children is regarded as excessive $^{(15)}$. A $24 \mathrm{~h}$ recall without estimation of quantities was used to collect samples of goat and camel milk ( $n$ 22) in the household where the children had been drinking milk the previous day. The iodine content in the milk was analysed by inductively couple plasma-MS ${ }^{(16)}$ at the Norwegian National Institute of Nutrition and Seafood Research (NIFES). The $Z$-scores for height-for-age (HAZ), weight-for-age (WAZ) and BMI-for-age (BMIZ) were calculated using WHO growth reference data from 2007 for children and adolescents aged 5-19 years ${ }^{(17)}$. Children were classified as stunted, underweight or with low BMIfor-age if their HAZ, WAZ or BMIZ was $<-2$, respectively.

\section{Data entry and statistics}

Data were entered and analysed using the SPSS version 14.0 (SPSS Inc., Chicago, IL, USA) and STATA 10 (StataCorp, College Station, TX, USA) statistical software packages. The data on Tvol, UIC and iodine in drinking water did not adhere to a normal distribution; descriptive statistics are therefore reported as median and 25th-75th percentiles $\left(\mathrm{P}_{25}-\mathrm{P}_{75}\right)$. Continuous variables were compared by the Mann-Whitney test or Spearman's rank correlation. Categorical variables were compared using the $\chi^{2}$ test. The difference in Tvol between households with and without livestock was measured in crude and adjusted multiple regression models and adjusted for age, height, weight and sex, as well as clustering on the households. In these models, Tvol was $\log _{\mathrm{e}}$-transformed to achieve normality. The comparison was made because of the high iodine concentration in milk. Two-tailed tests with a significance level of 5\% were used throughout. Every eligible child in a household was included; to adjust for clustering within the households, we used the SVY group of commands in STATA which fits statistical models for complex survey data. 


\section{Results}

Characteristics of the children and their households are shown in Tables 1 and 2, respectively. Mean age of the children was 10 years. In total, $21 \%$ of the children were underweight, 24\% were stunted and 9\% had low BMIfor-age. Respectively $11 \%$ and $28 \%$ of the children had been suffering from diarrhoea (more than 3 loose stools/ d) or fever/cough during the last two weeks. Local goat and camel milk had been drunk by $23 \%$ of the children the previous day. The mean number of children in the household was 6 (SD 3). In total $87 \%$ of the households had animals, where goat and sheep were most common. Only $8 \%$ of the households had their own or access to a vegetable garden and were cultivating vegetables. Almost all the households had their own brick kitchen and $75 \%$ had their own latrine.

Figures 1 and 2 show the median Tvol-for-age and Tvol-for-BSA in the children compared with the international reference values for $\mathrm{Tvol}^{(11)}$. Table 3 shows the median Tvol in each age group as well as Tvol-forage $>\mathrm{P}_{97}$. The prevalence of goitre based on Tvol-for-age was $56\left(95 \%\right.$ CI 49, 63) \%. Median $\left(\mathrm{P}_{25}-\mathrm{P}_{75}\right)$ Tvol progressively increased with age, from $3 \cdot 0(2 \cdot 6-3 \cdot 7) \mathrm{ml}$ in 6-year-old children to $7 \cdot 8(6 \cdot 5-9 \cdot 3) \mathrm{ml}$ in 14 -year-old

Table 1 Characteristics of the Saharawi children sampled ( $n$ 421), 2007

\begin{tabular}{lcc}
\hline Characteristic & Mean & SD \\
\hline Age (years) & 10 & $2 \cdot 6$ \\
& $n$ & $\%$ \\
\cline { 2 - 3 } & & \\
Nutritional status* & 49 & 21 \\
$\quad$ Underweight (WAZ $<-2) \dagger$ & 102 & 24 \\
Stunting (HAZ $<-2)$ & 38 & 9 \\
Low BMI-for-age (BMIZ $<-2)$ & 45 & 11 \\
Diarrhoea during the last two weeks & 118 & 28 \\
Fever/cough during the last two weeks & 98 & 23 \\
Drunk milk the previous day & &
\end{tabular}

WAZ, weight-for-age Z-score; HAZ, height-for-age Z-score; BMIZ, BMI-forage $Z$-score.

*Nutritional status assessed on the basis of the WHO growth reference data from 2007 for children and adolescents aged 5-19 years $^{(17)}$.

tChildren $<10$ years old $(n 231)$.

Table 2 Characteristics of the Saharawi households sampled (n 92), 2007

\begin{tabular}{lcc}
\hline Characteristic & Mean & SD \\
\hline Number of children & 6 & 3 \\
Number of family members & 11 & 5 \\
& \multicolumn{1}{c}{$\frac{}{20}$} & $\%$ \\
\cline { 2 - 2 } & 80 & 87 \\
Vegetable garden & 7 & 8 \\
Kitchen & 89 & 97 \\
Latrine & 69 & 75 \\
\hline
\end{tabular}

children $\left(r_{\mathrm{S}}=0.68, \quad P<0.001\right)$. The prevalence of goitre based on Tvol-for-BSA was 86 (95\% CI 82, 90) \% (Table 4). Median $\left(\mathrm{P}_{25}-\mathrm{P}_{75}\right)$ Tvol increased with BSA, from $3 \cdot 1(2 \cdot 6-3 \cdot 9) \mathrm{ml}$ in children with BSA of $0 \cdot 7 \mathrm{~m}^{2}$ to $9 \cdot 8(6 \cdot 7-16 \cdot 2) \mathrm{ml}$ in children with BSA of $1.6 \mathrm{~m}^{2}\left(r_{\mathrm{S}}=\right.$ $0 \cdot 74, P<0 \cdot 001)$. No significant association was found between sex and goitre. Children who were suffering from stunting, underweight and low BMI-for-age had lower Tvol than children with normal height and weight for their age $(P<0 \cdot 001, P<0 \cdot 001$ and $P=0 \cdot 02$, respectively).

Figure 3 shows the frequency distribution of the UIC. None of the children had UIC below $100 \mu \mathrm{g} / 1,16 \%$ of the children had UIC between 100 and $299 \mu \mathrm{g} / 1,28 \%$ between 300 and $499 \mu \mathrm{g} / \mathrm{l}$, and $38 \%$ between 500 and $999 \mu \mathrm{g} / \mathrm{l}$. Eighteen per cent of the children had UIC above $1000 \mu \mathrm{g} / \mathrm{l}$. The median $\left(\mathrm{P}_{25}-\mathrm{P}_{75}\right)$ UIC for the children was $565(357-887) \mu \mathrm{g} / \mathrm{l}$.

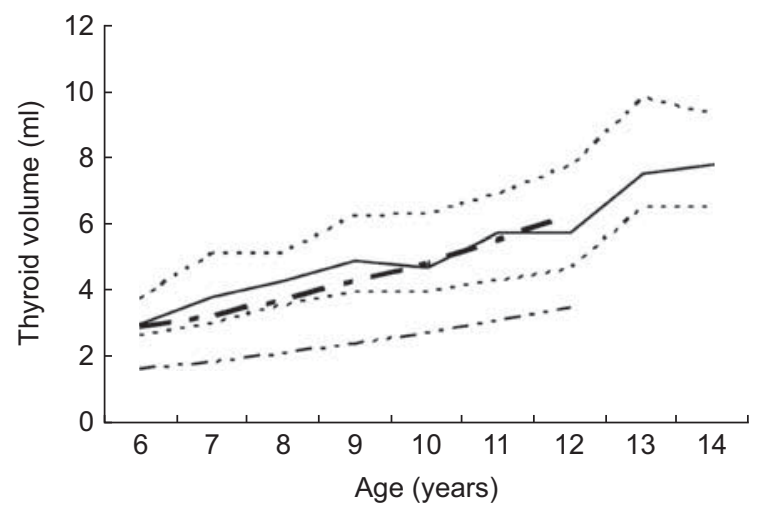

Fig. 1 Median (-), 25th percentile (- - ) and 75th percentile (- - -) values of thyroid volume by age in Saharawi children ( $n$ 333), in 2007, compared with the median (-.--) and 97th percentile $(---)$ of the 2004 international reference values from the WHO/International Council for the Control of lodine Deficiency Disorders ${ }^{(11)}$

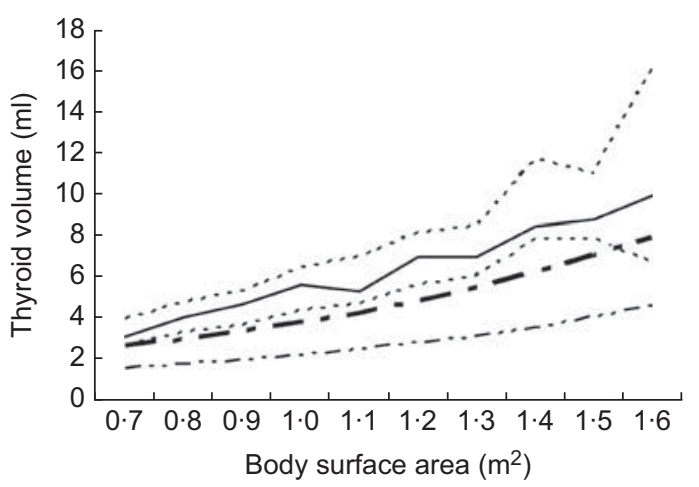

Fig. 2 Median (-), 25th percentile (- - -) and 75th percentile (- - ) values of thyroid volume by body surface area in Saharawi children ( $n$ 397), in 2007, compared with the median $(-\cdots-)$ and 97 th percentile $(--)$ of the 2004 international reference values from the WHO/International Council for the Control of lodine Deficiency Disorders ${ }^{(11)}$ 
The median $\left(\mathrm{P}_{25}-\mathrm{P}_{75}\right)$ iodine concentration in drinking water among the ninety-two households was 108 (77-297) $\mu \mathrm{g} / 1$. Iodine concentration in drinking water correlated significantly with UIC $\left(r_{\mathrm{S}}=0.63, P<0 \cdot 001\right)$. The median $\left(\mathrm{P}_{25}-\mathrm{P}_{75}\right)$ iodine content in milk was 595 (245-1375) $\mu \mathrm{g} / 1$ ( $n$ 22).

Tvol was 15\% (95\% CI 6, 24\%,P=0.001) higher in households with livestock after adjusting for age, height, weight and sex.

\section{Discussion}

Our study revealed a high prevalence of goitre among the Saharawi children and high levels of UIC and iodine in drinking water. The endemic goitre seems therefore to

Table 3 Tvol and Tvol-for-age $>P_{97}$ in Saharawi children aged 6-14 years, 2007

\begin{tabular}{lcccccc}
\hline & & \multicolumn{2}{c}{ Tvol $(\mathrm{ml})$} & & \multicolumn{2}{c}{ Tvol-for-age $>\mathrm{P}_{97}$} \\
\cline { 7 - 7 } Age (years) & $n$ & Median & $\mathrm{P}_{25}-\mathrm{P}_{75}$ & & $n$ & $\%$ \\
\hline 6 & 55 & $3 \cdot 0$ & $2 \cdot 6-3 \cdot 7$ & & 32 & $58 \cdot 2$ \\
7 & 44 & $3 \cdot 8$ & $3 \cdot 0-5 \cdot 1$ & & 29 & $65 \cdot 9$ \\
8 & 41 & $4 \cdot 3$ & $3 \cdot 5-5 \cdot 1$ & & 28 & $68 \cdot 3$ \\
9 & 51 & $4 \cdot 9$ & $3 \cdot 9-6 \cdot 2$ & & 35 & $68 \cdot 6$ \\
10 & 39 & $4 \cdot 7$ & $3 \cdot 9-6 \cdot 3$ & & 15 & $38 \cdot 5$ \\
11 & 45 & $5 \cdot 7$ & $4 \cdot 3-6 \cdot 9$ & & 22 & $48 \cdot 9$ \\
12 & 58 & $5 \cdot 7$ & $4 \cdot 6-7 \cdot 7$ & & 26 & $44 \cdot 8$ \\
13 & 42 & $7 \cdot 5$ & $6 \cdot 5-9 \cdot 8$ & & - \\
14 & 44 & $7 \cdot 8$ & $6 \cdot 5-9 \cdot 3$ & & - \\
Total & $419^{*}$ & $5 \cdot 0$ & $3 \cdot 8-6 \cdot 9$ & & $187+$ & $56 \cdot 2$ \\
\hline
\end{tabular}

Tvol, thyroid volume; $P_{97}, 97$ th percentile; $P_{25}, 25$ th percentile; $P_{75}, 75$ th percentile.

*Data missing for two children.

tInternational reference values for Tvol-for-age ${ }^{(11)}$ exist only for children aged $6-12$ years ( $n 333) ; 187$ of the 333 children were classified with goitre. be caused by iodine excess rather than deficiency. These results are in accordance with previous studies in the area $^{(3,6)}$. Previous studies ${ }^{(4,6)}$ and our study have revealed high levels of naturally occurring iodine in the drinking water. Our study also revealed high concentration of iodine in animal milk and there was a positive association between Tvol and the presence of livestock in the household. This suggests that water and milk are the main sources of the excess iodine excretion.

The prevalence of goitre based on Tvol-for-BSA was higher $(86 \%)$ than the prevalence of goitre based on Tvol-for-age (56\%). It is suggested that Tvol-for-BSA should be used in areas with high prevalence of malnutrition with both stunting and underweight ${ }^{(15)}$. These

Table 4 Tvol as a function of BSA from $0 \cdot 7$ to $1.6 \mathrm{~m}^{2}$ and Tvol-forBSA $>P_{97}$ in Saharawi children aged 6-14 years, 2007

\begin{tabular}{|c|c|c|c|c|c|}
\hline \multirow[b]{2}{*}{$\mathrm{BSA}\left(\mathrm{m}^{2}\right)$} & \multirow[b]{2}{*}{$n$} & \multicolumn{2}{|c|}{ Tvol (ml) } & \multicolumn{2}{|c|}{ Tvol-for-BSA $>\mathrm{P}_{97}$} \\
\hline & & Median & $\mathrm{P}_{25}-\mathrm{P}_{75}$ & $n$ & $\%$ \\
\hline 0.7 & 46 & $3 \cdot 1$ & $2 \cdot 6-3 \cdot 9$ & 36 & $78 \cdot 3$ \\
\hline 0.8 & 61 & $4 \cdot 0$ & $3 \cdot 3-4 \cdot 7$ & 51 & $83 \cdot 6$ \\
\hline 0.9 & 70 & $4 \cdot 6$ & $3 \cdot 6-5 \cdot 3$ & 59 & $84 \cdot 3$ \\
\hline $1 \cdot 0$ & 56 & $5 \cdot 5$ & $4 \cdot 4-6 \cdot 4$ & 52 & $92 \cdot 9$ \\
\hline $1 \cdot 1$ & 47 & $5 \cdot 3$ & $4 \cdot 6-7 \cdot 0$ & 40 & $85 \cdot 1$ \\
\hline $1 \cdot 2$ & 49 & $6 \cdot 9$ & $5 \cdot 6-8 \cdot 1$ & 42 & $85 \cdot 7$ \\
\hline $1 \cdot 3$ & 37 & $7 \cdot 0$ & $6 \cdot 0-8 \cdot 4$ & 32 & 86.5 \\
\hline $1 \cdot 4$ & 16 & $8 \cdot 4$ & $7 \cdot 8-11 \cdot 7$ & 16 & $100 \cdot 0$ \\
\hline $1 \cdot 5$ & 8 & $8 \cdot 8$ & $7 \cdot 7-10 \cdot 9$ & 8 & $100 \cdot 0$ \\
\hline $1 \cdot 6$ & 7 & $9 \cdot 8$ & $6 \cdot 7-16 \cdot 2$ & 4 & $57 \cdot 1$ \\
\hline Total & $397^{\star}$ & $6 \cdot 3$ & $5 \cdot 2-7 \cdot 5$ & $340 t$ & $85 \cdot 6$ \\
\hline
\end{tabular}

Tvol, thyroid volume; $B S A$, body surface area; $\mathrm{P}_{97}, 97$ th percentile; $\mathrm{P}_{25}, 25$ th percentile; $\mathrm{P}_{75}$, 75th percentile.

*International reference values for Tvol-for-BSA ${ }^{(11)}$ exist only for children with BSA of 0.7 to $1.6 \mathrm{~m}^{2}$ ( $n$ 397). In total, twenty-one of the children had lower BSA than $0.7 \mathrm{~m}^{2}$ and one child had higher than $1.6 \mathrm{~m}^{2}$. †340 of the 397 children were classified with goitre.

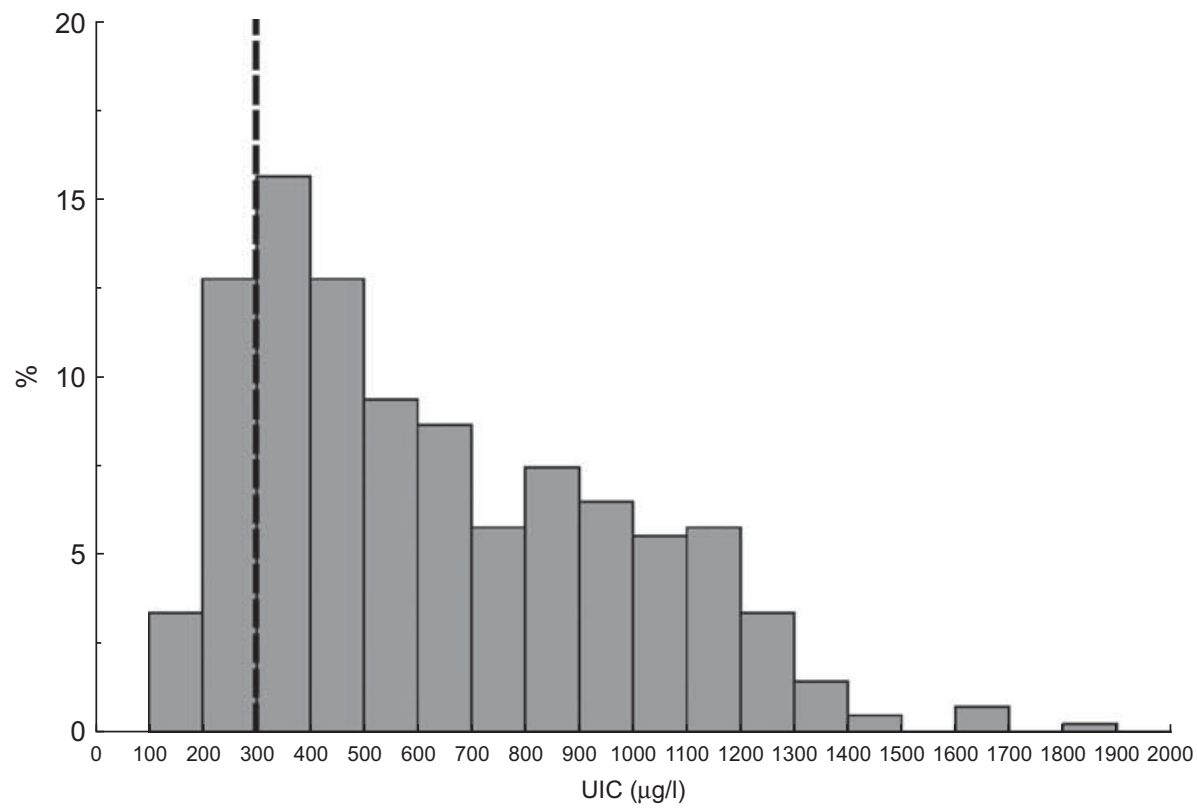

Fig. 3 Frequency distribution of urinary iodine concentration (UIC, $\mu \mathrm{g} / \mathrm{l})$ in Saharawi children ( $n$ 415), in 2007. The dashed line indicates the cut-off limit for excessive UIC. One outlier (UIC = $3594 \mu \mathrm{g} / \mathrm{I})$ is excluded 
children had a high prevalence of malnutrition and therefore the reference values for Tvol-for-BSA are considered most reliable. A study conducted in 1998 among the Saharawi refugees showed a prevalence of goitre of $28 \%{ }^{(4)}$. Another study from 2003 revealed a prevalence of goitre of $58 \%{ }^{(6)}$. Seemingly, the prevalence of goitre has increased; however, these earlier studies were based on palpation, not on ultrasound, and are therefore not directly comparable with our study. Tvol measurements by ultrasound are more sensitive to detect enlargements of the thyroid gland than palpation and it is therefore expected to find higher prevalence when using this methodology ${ }^{(13)}$. In our study, Tvol increased with age, height and weight whereas no difference between the sexes was found. This is in accordance with previous findings ${ }^{(18,19)}$. Goitre can be aggravated by malnutrition and water-borne goitrogens ${ }^{(20)}$. The high level of malnutrition among the children can have influenced the development of goitre. We found, however, that malnourished children had lower Tvol than wellnourished children. A study among the refugees showed that thiocyanate in drinking water and urine was within normal levels ${ }^{(6)}$.

The median UIC among the children $(565 \mu \mathrm{g} / \mathrm{l})$ considerably exceeds the WHO's cut-off value for excessive UIC of $300 \mu \mathrm{g} / \mathrm{l}^{(15)}$. High levels of urinary iodine may originate from water, food (such as meat and milk or from natural sources such as seaweed), medications, disinfectants and contrast media ${ }^{(2,21)}$. Within refugee populations that are dependent on food aid, iodine status is also dependent on the iodine content of the food ration ${ }^{(5)}$. Typical food items that are distributed in the Saharawi refugee camps are cereals, lentils, oil, sugar, and blended fortified cereal foods. However, the iodine content of these food items is modest in comparison with the iodine levels that were discovered in water and milk. Our study revealed that children from households with livestock had higher Tvol than those without livestock. This might be due to higher intake of milk among these children. Both rock salt and fine salt were used in the camps, but this salt also contained low levels of iodine compared with iodine levels in water and milk. The only iodine supplementation the children received was $35 \mathrm{~g}$ of fortified biscuits which contained $13 \mu \mathrm{g}$ of iodine. They were distributed daily at school, but are not believed to have influenced the iodine intake considerably.

The high iodine content of the drinking water $(108 \mu \mathrm{g} / 1)$ largely exceeds normal levels of iodine in drinking water of $<15 \mu \mathrm{g} / \mathrm{l}^{(22)}$. Compared with earlier studies, however, the levels seem to have decreased. A study among the refugees from 1998 showed an iodine concentration in drinking water that ranged from 259 to $934 \mu \mathrm{g} / \mathrm{l}^{(4)}$, while a study from 2003 showed the range of iodine concentration in drinking water to be $180-400 \mu \mathrm{g} / \mathrm{l}^{(6)}$. The reduction of iodine in drinking water is probably due to the introduction of new water wells during the last 3-5 years and to routine water purification.
For example, one of the camps has received purified water from a reverse osmotic plant for the last 3 years ${ }^{(23)}$. Half of the households had an iodine concentration in drinking water above $150 \mu \mathrm{g} / \mathrm{l}$ and a quarter of the households had this concentration above $300 \mu \mathrm{g} / 1$ (data not shown). Thus a daily water intake of 1 litre would exceed the WHO limit for recommended iodine intake for children aged $6-12$ years $(120 \mu \mathrm{g} / \mathrm{d})^{(15)}$ and in a quarter of the households would exceed the tolerable upper intake limit of $300 \mu \mathrm{g} / 1$ in children aged $4-8$ years $^{(24)}$.

These children have probably been exposed to high levels of iodine since birth. However, our study was not designed to examine whether the high iodine intakes could have had negative health effects for the children. Previous studies of thyroid hormones (thyroid-stimulating hormone, triiodothyronine, thyroxine) and autoimmunity (thyroperoxidase antibodies) among the children demonstrated normal thyroid function despite high levels of iodine in drinking water and urine ${ }^{(6)}$. It is established that low levels of urinary iodine are associated with iodinedeficiency disorders ${ }^{(25)}$. To what degree this association also exists for excessive intakes is unclear. Several studies have found increased Tvol induced by iodine excess ${ }^{(7,8,21,26)}$, but few studies have been conducted to investigate the effect of prolonged exposure to high intakes ${ }^{(27)}$.

In conclusion, the current study has shown that Saharawi children are suffering from endemic goitre and have high levels of iodine in drinking water and urinary iodine. The high iodine intakes probably come from the drinking water and milk. Further studies are required to determine to what extent the high iodine intake and urinary iodine excretion have resulted in negative health consequences for the children. Interventions to reduce the content of iodine in the drinking water should be strengthened.

\section{Acknowledgements}

This work was supported by the Norwegian Research Council (grant number 172226/S30). The authors have no conflicts of interest to disclose. S.H. participated in designing the study and the data collection, and took the lead in analysing, interpreting and writing the manuscript. I.B. and A.K.G. participated in the planning, data collection, analysis and writing. A.M.-L. participated in the planning and data collection and reviewed the manuscript. A.O., T.A.S. and L.E.T. contributed to the study design and analyses, as well as to the writing of the manuscript. The authors wish to acknowledge the support provided by Dr Juan José Arrizabalaga and Dr Gurutz Larrañaga Hernando at the hospital Txagorritxu in Vitoria-Gasteiz, Spain. They did the ultrasound training and provided important advice during the fieldwork. Our thanks also go to the fieldworkers and to the Saharawi families who patiently answered the questions and inquiries. 


\section{References}

1. Laurberg P, Bulow Pedersen I, Knudsen N et al. (2001) Environmental iodine intake affects the type of nonmalignant thyroid disease. Thyroid 11, 457-469.

2. Pennington JA (1990) A review of iodine toxicity reports. I Am Diet Assoc 90, 1571-1581.

3. United Nations High Commissioner for Refugees, World Food Programme \& Centre for International Child Health, Institute of Child Health (2001) Anthropometric and Micronutrient Nutrition Survey, Saharawi Refugee Camps, Tindouf, Algeria, September 2002. http://www.unhcr.org/ 45fa67bf2.html (accessed March 2010).

4. Pezzino V, Padova G, Vigneri R et al. (1998) Iodineindependent endemic goiter in Saharawi refugee camps in Southwestern Algeria. IDD Newsl 14, 12-13.

5. Seal AJ, Creeke PI, Gnat D et al. (2006) Excess dietary iodine intake in long-term African refugees. Public Health Nutr 9, 35-39.

6. Díaz-Cadórniga FJ, Delgado E, Tartón T et al. (2003) Bocio endémico por exceso de yodo en la población escolar de los campos de refugiados de la RASD (República Árabe Saharaui Democrática). Endocrinol Nutr 50, 357-362.

7. Li M, Liu DR, Qu CY et al. (1987) Endemic goitre in central China caused by excessive iodine intake. Lancet 2, 257-259.

8. Suzuki H, Higuchi T, Sawa K et al. (1965) 'Endemic coast goitre' in Hokkaido, Japan. Acta Endocrinol (Copenh) 50, $161-176$.

9. World Health Organization, UNICEF \& International Council for the Control of Iodine Deficiency Disorders (1994) Indicators for Assessing Iodine Deficiency Disorders and their Control Programs through Salt Iodization. Geneva: WHO.

10. Brunn J, Block U, Ruf G et al. (1981) [Volumetric analysis of thyroid lobes by real-time ultrasound]. Dtsch Med Wochenschr 106, 1338-1340.

11. Zimmermann MB, Hess SY, Molinari L et al. (2004) New reference values for thyroid volume by ultrasound in iodinesufficient schoolchildren: a World Health Organization/ Nutrition for Health and Development Iodine Deficiency Study Group Report. Am J Clin Nutr 79, 231-237.

12. World Health Organization (1995) Physical Status: The Use and Interpretation of Anthropometry. Geneva: WHO.

13. Zimmermann M, Saad A, Hess S et al. (2000) Thyroid ultrasound compared with World Health Organization 1960 and 1994 palpation criteria for determination of goiter prevalence in regions of mild and severe iodine deficiency. Eur J Endocrinol 143, 727-731.

14. Sandell EB \& Kolthoff IM (1937) Micro determination of iodine by catalytic method. Mikrochim Acta 1, 9-15.
15. World Health Organization, UNICEF \& International Council for the Control of Iodine Deficiency Disorders (2007) Assessment of Iodine Deficiency Disorders and Monitoring their Elimination. Geneva: WHO.

16. Haldimann M, Eastgate A \& Zimmerli B (2000) Improved measurement of iodine in food samples using inductively coupled plasma isotope dilution mass spectrometry. Analyst 125, 1977-1982.

17. de Onis M, Onyango AW, Borghi E et al. (2007) Development of a WHO growth reference for school-aged children and adolescents. Bull World Health Organ 85, 660-667.

18. Vitti P, Martino E, Aghini-Lombardi F et al. (1994) Thyroid volume measurement by ultrasound in children as a tool for the assessment of mild iodine deficiency. I Clin Endocrinol Metab 79, 600-603.

19. Rossi A, Tomimori E, Camargo R et al. (2002) Determination of thyroid volume by sonography in healthy Brazilian schoolchildren. J Clin Ultrasound 30, 226-231.

20. Gaitan E (1990) Goitrogens in food and water. Annu Rev Nutr 10, 21-39.

21. Pearce EN, Gerber AR, Gootnick DB et al. (2002) Effects of chronic iodine excess in a cohort of long-term American workers in West Africa. J Clin Endocrinol Metab 87, 5499-5502.

22. European Commission, Scientific Committee on Food (2002) Opinion of the Scientific Committee on Food on the Tolerable Upper Intake Level of Iodine. Brussels: European Commission.

23. Gjerlaug AK (2007) Struma blant saharawiske flyktninger $i$ Algerie - for lite eller for mye jod? Oslo: Akershus University College.

24. Institute of Medicine (2001) Dietary Reference Intakes for Vitamin A, Vitamin K, Arsenic, Boron, Chromium, Copper Iodine, Iron, Manganese, Molybdenum, Nickel, Silicon, Vanadium and Zinc: A Report of the Panel on Micronutrients, Subcommittees on Upper Reference Levels of Nutrients and Interpretation and Uses of Dietary Reference Intakes, and the Standing Committee on the Scientific Evaluation of Dietary Reference Intakes. Washington, DC: National Academy Press.

25. Dunn JT, Crutchfield HE, Gutekunst R et al. (1993) Two simple methods for measuring iodine in urine. Thyroid $\mathbf{3}$, $119-123$

26. Namba H, Yamashita S, Kimura H et al. (1993) Evidence of thyroid volume increase in normal subjects receiving excess iodide. J Clin Endocrinol Metab 76, 605-608.

27. Zimmermann MB, Ito Y, Hess SY et al. (2005) High thyroid volume in children with excess dietary iodine intakes. $\mathrm{Am} \mathrm{J}$ Clin Nutr 81, 840-844. 